\title{
Personal Knowledge Management and M-learning in the Learning Society
}

\author{
Shuying Zhuang \\ Jilin University of Finance and Economics, Changchun, Jilin Province, China \\ zsyzsyhome@163.com
}

Keywords: Personal knowledge management (PKM); Learning society; Lifelong learning; $M-$ learning (mobile learning)

\begin{abstract}
Living in a networked and digitalized learning society, people need to study lifelong to perfect their knowledge system and adapt to the development and changes of the society. But with vast amount of resources available, efficient learning is a matter worth studying. This paper first briefly analyzes the policies of several influential world organizations and China to illustrate that lifelong learning is being attached great importance to and is regarded as an important strategy to accept the challenges as well as to solve the problems in the educational sector in the learning society. Then it discusses that personal knowledge management (PKM) is the technique that must be mastered by people in the learning society on the basis of Mayer's learning process model and SECI model by Japanese scholars. Lastly, it discusses that M-learning is a new way of learning. The advanced telecommunications technology provides technical support for people to manage personal knowledge in an M-learning context. Thus, M-learning combined with PKM techniques constitute an information quality for people to compete or even survive in the lifelong learning society.
\end{abstract}

\section{INTRODUCTION}

In the modern society, with the development of economy as well as the science and technology, we can get access to vast amount of information via the internet, computers and many electronic media. Living in a networked and digitalized society, learning consistently for the whole life (lifelong learning) is needed in order to adapt to the dynamic society which is undergoing changes and development with each passing day. We also need to cultivate the ability of selecting and processing information. Thus, knowing how to learn becomes even more important than learning itself. Chen Guisheng once said in On Lifelong Education that current education (or study) was indeed not merely confined to the mastering of the existing knowledge, but lied in knowing how to learn and that is a must for people to survive in the competitive modern society. A concept advanced by UNESCO in a report titled Learning to Be in 1972 was: Life was actually a process of continual learning and improvement of oneself. We need to learn lifelong in order to build an evolutionary knowledge system---learning to survive in the society.

\section{THE IMPORTANCE OF LIFELONG LEARNING IN THE LEARNING SOCIETY --- FROM POLICY PERSPECTIVE}

During the past decades, some influential world organizations and different countries have been advocating lifelong learning and establishment of learning society. Their policies have imposed great impact on the educational reform in different countries, showing the importance of lifelong learning in the learning society.

\section{A. Relative Reports on Lifelong Learning Policies by UNESCO(overview)}

1972, Learning to Be ---First introduced the notion of lifelong learning and learning society.

1976, Recommendation on Development of Adult Education---Gave three suggestions on developing lifelong learning.

1996, learning: the Treasure within---Based on lifelong learning, the concept of four supporting pillars for education was put forward. The four pillars are: learning to know, learning to do, learning to live together and learning to be. Especially, the core ability is learning how to learn. Learning how to learn means learning to be, learning to develop and learning to adapt to and keep pace with the development and changes in the society. 
1997,Comparative studies on Lifelong Learning---Identifying 29 indicators of lifelong learning including global transition indicators such as the impact of lifelong learning.

1997, The Hamburg Declaration on Adult Leaning Policies and Agenda for Future of Adult Leaning---Advocate cultivating the ability to adapt to the environment and initiating an activity of "everyday learning for one hour" .

1999, Cologne Declaration--- Lifelong Learning Goals and Prospects---Countries in the world are faced with the same problem of constructing learning society.

2000, Dakar Framework for Action---New information and telecommunication technology are necessary for achieving the goal of lifelong education for all.

2003, Nurturing the Treasure: Vision and Strategy2002-2007---Learning to change (or adapt to the society) should be the fifth supporting pillar of education in addition to the four pillars identified in the previous report.

2009, Belem Action Framework---lifelong learning is important in solving the problems in the education sector and helps to respond to challenges.

B. Relative Reports on Lifelong Learning Policies by Organization for Economic Cooperation and Development (OECD)

OECD published several reports such as Knowledge- Base Economy and Education Policy Analysis pointing out that knowledge and science and technology were the core part of the economic development and knowledge management was an important technique and that lifelong learning was a critical strategy towards knowledge-based economy.

\section{Relative Reports on Lifelong Learning by EU(the European Union)}

EU also holds that cultivating the ability to survive and develop should be one of the top priorities. In 2002, EU released Report on Lifelong Learning Quality Indicators for Europe. It summarizes eight key abilities needed by the people to respond to the challenges from the information society. And the ability to apply information and computer technology and the ability to know how to learn are two of them.

\section{China's practice}

Different countries adopted their own measures to advocate lifelong learning and China was no exception. China published documents such as Education Law of the People's Republic of China and the Tenth Five-year Plan for the Education Sector, etc., emphasizing lifelong learning and the necessity of constructing learning society as well as the construction of lifelong education system with Chinese characteristics.

It was also reported that in 1993, China wanted to increase its spending on education to $4 \%$ of its GDP in order to make China a learning society. Though this goal was not achieved as scheduled, China was determined to do so. In 2009, China set a plan of increasing the investment to some US\$200 billion on education reform including developing non-formal education facilities to implement lifelong learning and digitalizing the learning processes by utilizing the advanced technology. [1]

\section{PERSONAL KNOWLEDGE MANAGEMENT IS A MUST-HAVE TECHNIQUE IN LEARNING SOCIETY}

\section{E. PKM is required by the changes in the learning society}

In the information age, information is increasing by huge amount and with fast speed. For example, Professor Peter Lyman and HalR.Varian analyzed sources of information and the research showed that the new information in 1992 alone could fill 500,000 Library of Congress in U.S. [2]

Obviously the classroom knowledge is far from enough to meet the needs of the public. In 1960s, Marshall McLuhan noted that most study nowadays is happening outside the classroom. The information is delivered much more in the newspapers, films and so on than in the classroom teaching and textbooks. Economist Herbent Simon once said that the scarcest resources now are not the information, but the ability to process it. 


\section{F. PKM is an effective and efficient technique for lifelong learning}

Cognitive theory states that knowledge can be classified as tacit and explicit knowledge. This was advanced by British economist Michael Polanyi. He thought that explicit knowledge such as truth and scientific knowledge could be expressed through languages, written materials, etc. and be used to communicate while tacit knowledge was hard to be expressed by languages and words and was obtained by recreation based on explicit knowledge. It was the understanding of things through longterm practice and reflection.

Based on Mayer's learning process model, we can see the relationship of learning resources, information and knowledge while an individual learns. First, there are resources available and then learners get access to the resources and obtain information. After that, information is processed to fulfill the aim of knowledge learning. This information processing procedure could be illustrated by SECI model based on knowledge Spiral theory which shows the conversion of knowledge. (Fig.1)

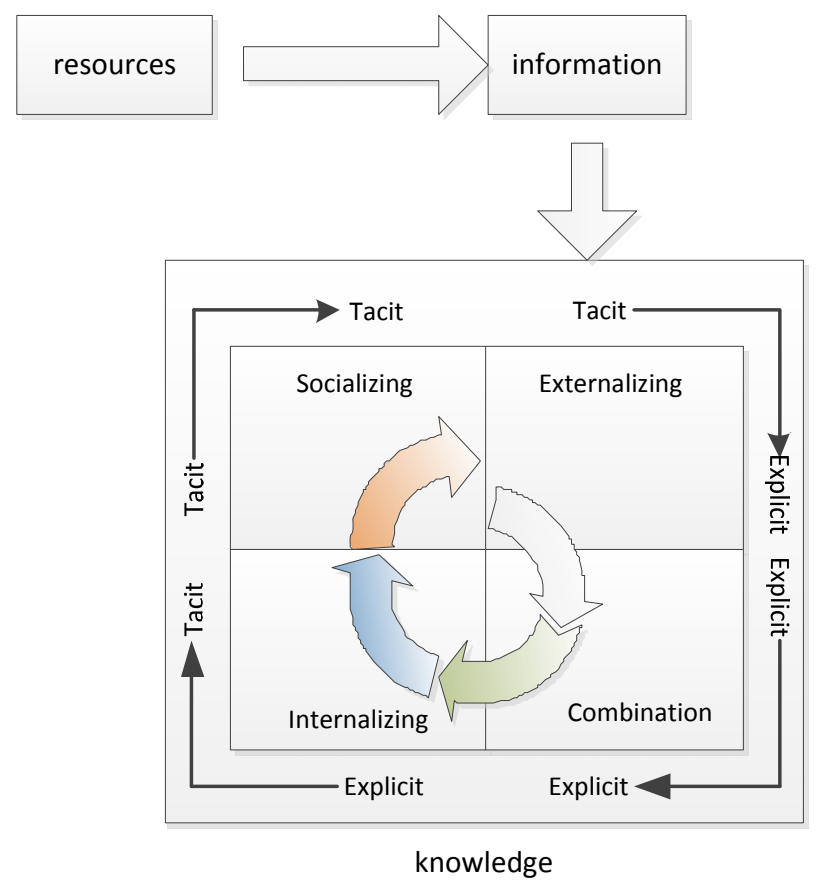

Fig. 1 Mayer’s learning process model and SECI model by Lkujro Nonaka and Takeuchi.

SECI model was constructed by Japanese scholar Lkujro Nonaka and Takeuchi. They thought that tacit and explicit knowledge kept interacting whereby knowledge was converted from one type to another. Four modes of knowledge conversion were identified including socialization, externalization, combination and internalization and were originally proposed to cope with the knowledge in companies. Personal knowledge conversion mainly concerns with the internalization (converting from explicit to tacit) and externalization (converting from tacit to explicit). Internalization means learners retrieve knowledge from resources available and then apply the gained explicit knowledge into practice to solve problems. Through understanding and reflection during the process, new tacit knowledge is formed, thus resulting in the conversion from explicit to tacit knowledge. Externalization means learners use written documents or images or other means to express reflection and understanding and thus enables the conversion from tacit to explicit knowledge, allowing it to be shared by other people. This then becomes the basis of the new knowledge and hence perfect individual's knowledge system.

Personal Knowledge Management (PKM) was first defined by American professor Paul Dorsey. He believed that it was "a set of problem-solving skills that have both a logical or conceptual or hands-on component”. Seven skills---retrieving, assessing, organizing, analyzing, presenting i n f o r m a t i o n, e n s u r i g the i n f ormation s a f e t y and collaborating around knowledge---should be mastered when managing knowledge.[3] Davenport and Prusak thought that PKM was a systematic attempt to create, gather, distribute, and 
use knowledge.[4] Thus a conclusion can be drawn here that PKM is a set of techniques used to integrate and utilize knowledge. Jason Frand and Carol Hixon noted that PKM is the organization and integration of important knowledge by individual and then incorporate what is gained into personal knowledge system. [5]

\section{PKM NEEDS THE REFORM ON LEARNING STRATEGY ---M-LEARNING}

Information is renewed quickly and increasing rapidly in digital learning environment and what is learned in classroom can not meet the social competition requirement. According to SECI model, Mlearning based on network and telecommunication technology will surely surpass classroom learning and learning under the desk-top computer context, hence becoming the major means of learning in the learning society.

Managing knowledge conversion involves approaches such as tracking and evaluation. In terms of internalization, M-learning environment enables people to quickly judge what kinds of knowledge is in shortage and get online help in time. Then PKM skills could be used at this stage to integrate knowledge acquired through M-learning and assess its application in the practice so that adjustment could be made according to the feedback. In terms of externalization, people could select knowledge more helpful for other people to solve problems under the M-learning context.

Three popular views are there concerning M-learning. Some think it is a kind of distance learning, others argue that it is the extension of digital learning; still others believe that it is the new leaning style with combination of education and technique under the networked and digital learning context. Desmond Keegan regards it as the third development stage following distance education and digitalized education.

M-learning is much emphasized by researchers in developed European and North American countries. Their objects are to develop education and improve learners PKM level and learning performance by new educational technologies. Some major projects are shown in Table I.

TABLE I. EXAMPLES OF MAJOR M-LEARNING PROJECTS

\begin{tabular}{|c|c|c|}
\hline \multirow[b]{3}{*}{1} & project & Uniwap M-learning \\
\hline & Researcher & University of Helsinki, Finland \\
\hline & \multicolumn{2}{|c|}{$\begin{array}{l}\text { Target: Use Wap technology in higher education } \\
\text { to create a mobile learning environment so that } \\
\text { teachers and students could visit learning } \\
\text { resources at any time and place via Wap mobile } \\
\text { phone or smart phone. }\end{array}$} \\
\hline \multirow[b]{3}{*}{2} & project & Mobi learn \\
\hline & researcher & $\begin{array}{l}\text { Joint efforts by } 5 \text { organizations in the U.K. Sweden and Italy. } \\
\text { Funded by EU's digital Europe Action Plan }\end{array}$ \\
\hline & \multicolumn{2}{|c|}{$\begin{array}{l}\text { Target: Use advanced mobile telecommunication techniques create a mobile learning } \\
\text { environment } \\
\text { and develop recourses for mobile learning }\end{array}$} \\
\hline \multirow{3}{*}{3} & project & Mobile phone language learning \\
\hline & researcher & Stanford Learning Lab \\
\hline & \multicolumn{2}{|c|}{$\begin{array}{l}\text { Target: Select language learning as the standpoint } \\
\text { And use mobile phones in teaching to develop } \\
\text { mobile learning module for foreign language } \\
\text { study. }\end{array}$} \\
\hline
\end{tabular}

The history of M-learning research is relatively short as compared to that of western countries. Mlearning was introduced by Desmond Keegan in his speech in Shanghai named From E-learning to M-learning. Researches in this field are mainly led by the Ministry of Education (MOE). Major projects include: 1) Higher Education Department, MOE pilot project---Mobile education theory and practice (2002-2005), which developed three platforms based on GSM network and mobile devices, GPRS, and ontology respectively; 2) MOE project---Mobile education, with joint efforts of Beijing 
University, Qinghua University and Beijing Normal University. The research goals are to set up Mobile education network and service stations in universities based on China Mobile's SMS and GPS platform to provide educational services and products of various kinds to participants of the program.

These projects fully represent the public's acceptance and awareness of M-learning in the learning society. The former British Prime Minister Toby Blair once said "education was the best economic policy and future lies in the combination of education with technology”. [6]

\section{CONCLUSION}

Abundant educational theories and information technology (telecommunication devices, network and computers) provide people with powerful technical support, while PKM is the technique to integrate and utilize personal knowledge system. The natural combination of them is the important channel towards knowledge innovation. Implementing lifelong learning by means of M-learning and with the help of PKM technology is necessary information quality of people in the competitive learning society.

\section{REFERENCES}

[1] Duosdorf. F. (2010, June,14). "China defines road map for becoming a learning society by 2020." Retrieved October 1, 2010, from The China

Education Blog: http://www.chinaeducationblog.com/education- reform-chinese-educationpolicy/2010-06-14/china-defines-road-map-for-becoming-a-learning-society-by-2020/

[2] Peter Lyman and Hal R. Varian, How much information , 2003 [ J] http: //www. sims. berkeley. edu /research/projects/how -much-info-2003 /2003.

[3] PaulA.Dorsey, What is PKM [J]. http: //www.millikin. edu/ webmaster/seminar/ pkm. html / December, 1999.

[4] Davenport and Prusak, Working knowledge, HBS Press, 1998.

[5] Jason Frand and Carol Hixon- Personal Knowledge Management: Who, What, Why, When, Where, How[ J]. 1999 http: //www. anderson.ucla. edu/faculty/jason. frand/ researcher/ speeches/PKM. html.

[6] Fushun Huang, Comparative Study on Lifelong Education [M].Taipei:Wunan Publishing Co., Ltd., 2003, 11.

[7] http://www.oecd.org

[8] http://www.unesco.org

[9] http://en.wikipedia.org/wiki/The_SECI_Model, 23, March,2012 